International Journal of Library \& Information Science (IJLIS)

Volume 7, Issue 1, January-February 2018, pp. 1-6, Article ID: IJLIS_07_01_001

Available online at

http://iaeme.com/Home/issue/IJLIS?Volume=7\&Issue=1

Journal Impact Factor (2016): 8.2651 (Calculated by GISI) www.jifactor.com

ISSN Print: 2277-3533 and ISSN Online: 2277-3584

(C) IAEME Publication

\title{
PLAGIARISM DETECTION AND PREVENTION: A STUDY
}

\author{
Ganesh Kumar Soni \\ Student, Department of LIS, University of Rajasthan, Jaipur, India
}

\begin{abstract}
In this paper we discuss about Plagiarism. What is Plagiarism? Their types, which citation it will be avoid, this papers main features are how to detect Plagiarism and how to prevent it and also difference between Plagiarism and Copyright infringement, Plagiarism and Ghostwriting. This article saying about effective Plagiarism detecting software's and this basis identify that how much work is real and other is fraud.
\end{abstract}

Key words: Plagiarism, Plagiarism Detection Software, Plagiarism Checking, Copyright Infringement, Ghostwriting.

Cite this Article: Ganesh Kumar Soni, Plagiarism Detection and Prevention: A Study. International Journal of Library \& Information Science, 7(1), 2018, pp. 1-6. http://iaeme.com/Home/issue/IJLIS?Volume=7\&Issue=1

\section{INTRODUCTION}

In the present age of information technology any information is not accessing so difficult. The user can access the information 24/7 days from anywhere in the world. But with the use of information, it's misuse is also increasing some authors are publishing work from other writers by their name with little changes, it called Plagiarism. Plagiarism involves submitting work created by a professional service (in whole /part) and used without attribution.

The word Plagiarism comes from the Latin word 'Plagiarius' which means "abducting or kidnapping", it literary means theft, taking material authored by author's and presenting as someone else. Plagiarism is the illegal and unethical copying of another's work, which is up as its own.

In other words, acts of innocous quoting and borrowing become criminal or at least unethical, when the debt of one author to another is not properly paid via credit evidently due the receiver.

Unfortunately, digitization made copy-peste Plagiarism and inappropriate reuse of source from the websites, online journals and other electronic media. Widespread "with in academia, Plagiarism by students, professors and research scholars is considered academic censure, up to and including expulsion" and researchers and professors usually where punished for Plagiarism by sanctions ranging from suspension to termination with losing their credibility and perceived integrity. 


\section{TYPES OF PLAGIARISM}

1. Delibarate Plagiarism - Deliberate Plagiarism is the simple and totaly wrong act of attempting to pass off someone else's work as your own.

2. Paraphrasing -This type of Plagiarism is a little more strategic. It involves reading a few texts, writing down a few key sentences, changing tha words around, and throwing in a few quotes and citations to throw your turor off the scent. Then you have the perfact essay, Right? Wrong!

3. Patchwork Paraphrasing - This is much the same as the above, except thet it involves reading from more books and 'Pathching' their ideas together.

4. Bluffing - This type of Plagiarism is Bluffing in the worst way, because you are pretending that you have ownership of certain ideas in order to fool others into thinking you know more than you do. In this Plagiarism reading books, journal articles, reports and reveals them in a new idea and is shown that they are different from them, but reality these thoughts are the same.

5. Stitching Sources - Stitching Source Plagiarism is within the "grey zone" because all the sources used are generally correctly cited, but the student has unsucceed to grow up their analytical power to enable them to work effectively and produce work that is truly their own. This is still Plagiarism, but is more likely to be accidental as a result of experience.

6. Self-Plagiarism - Self-Plagiarism refers to reuse his own work. The author can piece of his old work together with his new work and produce a successful amalgam. But can't get two grades for the same things/works, so even if you do this without knowing that it's wrong. It is still classed as Plagiarism.

\section{PLAGIARISM V/S GHOSTWRITING}

Plagiarism and Ghostwriting are related kinds of conduct in which the true author's name is concealed the distinction between Plagiarism and Ghostwriting.

A Plagiarism copies text without permission of the true author.

A Ghostwriter knowingly and willingly produce text to appear as someone else's speech or writing.

A Plagiarist does not pay the real author for his services, while a ghostwriter is always give a payment for his work.

The academic community make no distinction between Plagiarism and Ghostwriting. Either way, the name of the true writers is deceitfully covered by the students and student represent to have written text that he did not write.

Ghostwriting is not so good, because all over text in article is from unidentified author, while routine fraud involves, some original writing selection of sources by the students who submitted the work.

\section{Plagiarism superior from Copyright infringements}

Many legal judgment have equated Plagiarism with copyright infringement but this concept is incorrect when we see the following three aspects --

- In copyright law the doctrine of fair use allows an author to copy small amount of text (small sentences or whole paragraph) without the need for permission from the copyright author. In Plagiarism, if any word/text used in the article have been indicate in a quotation mark. When some words are copied without declaration of a quatations. The wrong in not copyright infringement, the false is failure to credit the words to the real author. However fair use will not secure the Plagiarists who copies much pages from a work into the Plagiarist's suspicious work. 
- In the copyright law one cannot break text that is in the public domain (Like copyright has expired, author disclaimed copyright, work of Govt) but in Plagiarism it's always prohibited to copy material and non-copyright text is also prohibited without the conformation of quotation.

- Copyright law protects no one facts and none of ideas in the copyright work. Copyright protect only for expression of idea but some Professional Societies, Universities, Center's include copying idea in their explanation of Plagiarism

According to above quotations we realise that Plagiarism is not copyright infragment always and every condition. The embracement of real authors name and bibliographic data the copying not Plagiarization, but copying is copyright infringement.

\section{How to avoid Plagiarism}

Many people know that Plagiarism is unethical, unfair and crooked activity and this is usually enough to prevent us from doing it. Many technics are available to avoid Plagiarism but for those who do anything, the outcomes can be unpleasant, many professionals lost his professional reputation when they Plagiarize.

There are discussed some simple steps while writing research papers to ensure that your document will be free of Plagiarism--

- Paraphrase: When you find any information that is correct for your research article then first read it and add it into your own language. Make sure that you don't copy literally more than two words in a raw from the found text. If you use more than two words in a row then you will use quotation marks.

- Cite: Citing is a most dynamic mode to avoid Plagiarism. Going with the document formating instructions like APA, MLA Chicago etc. used by your educational institution. This generally require the addition of the authors and the date of publication or corrective information. Not citing properly can make Plagiarism.

- Quoting: Use the reference correctly the way it appears. No one wants to be misquote. Most educational communities of higher learning frown on "Block quotes" or reference's of 40 words or more. A student should be able to dramatically paraphrase most material. The reference's necessary done correctly to avoid Plagiarism allegations.

- Citing Quotes: This practice generally denote addition of page number, paragraph number in citation of web content.

- Citing your own material (Self Plagiarism): If your research article represent you own words/ideas, which related from your ongoing project, an earlier one or anywhere else you must cite yourself. Use the content as you like it someone else wrote it. It may sound odd but using information you have used before is called self-plagiarism and it is not delightful.

- Referencing: it need to use reference page of works at the end at your research article and this page in some as the document formatting instructions used by your research institutions. The reference are include the author details, date of publication, title and source. Follow the direction and get the right reference.

\section{Why Plagiarism detecting}

Plagiarism has a serious problem in present era. There are many examples of double published articles (in different journals) papers, and thesis. Plagiarism not only unethical, unfair, but also creates a problem for the real author, once he situate his work in another articles.

Unfortunately, when one reports a case of censure, one can't be sure of its importance. A search of the Internet indicates that there is more concern about cheating among students than among faculty. When title were scan, $90 \%$ of the article dealt with students and detection method of Plagiarism. This lack of articles on "Plagiarism among college faculty" could 
indicate either that there is little Plagiarism among faculty or they are not willing to admit that there is a program of Plagiarism among faculty.

The most way to detect Plagiarism is to use online available tools, mainly software and online Plagiarism Checking Services. We are going to describe some such Plagiarism Detecting and Preventing softwares which are commonly use -

1. Safe Assign: Safe Assign provided by 'Mydropbox'. Safe Assign is based on a unique text matching algorithms capable of detecting exact and inexact matching between a submitted papers and source material, students submission to safe Assign are compared against several sources --

- Institutional Document Archives.

- Global Reference Database

- Pro Quest Journal Database

- Internet

Safe Assign a system that can perform both local and Internet detecting.

2. Docol@c- This Internet service provides by Institut fur Argewandte Lentechnolgien (IFALT). This plagiarism finding tools is searching for text fragments also available in other documents. Documents will be uploaded to Docol@c for an extensive reviews by software programme and large database. As a result you get plagiarism, copyright infringements, quotations or other sources of the documents in the web.

There are three step's to use it - (1) Log in

(2) Upload Paper

Download Report

Docol@c provides the open access plagiarism search (OAPS) project. This type online service not any more available.

3. Plagiarism Finder:- It installs in to the user's computer and searches the internet for possible occurrences of text fragment from the local document collection. It detecting duplicate contents not only online tools, but also to it on proprietary database.

4. Duplichecker:- Duplichecker is the free online plagiarism checking software developers of this software tells like that it is $100 \%$ accurately Duplichecker software provide a statistical result of each text scan by user and provide a comprehensive analysis of his text.

5. Viper Plagiarism Checker: - Viper is a web based piece of software. Viper is easy to use interface and highly detailed scanning process. It only takes three simple steps- Check, Scan and Compare, with 10 Billion sources (including books, journal articles, websites and much more) to review your document and produce a full Plagiarism report. It launch in 2007, with a sample 'Drug and Drop'. Screening interface, easy to understand scan result and a free option available.

6. Plagiarism Detector:- Plagiarism detector is a software to detect plagiarism in online and offline documents this software mostly used to check for plagiarism in text document. It is fast a reliable plagiarism checker! This software detect the 1000 words online at a time. It's mainly task is the automatic detection of digital plagiarism (That is unofficial copy-paste or textual facts) that originated from the world wild web.

7. PlagTracker.com: - PlagTracker.com is the perfect free web based tool. PlagTracker is completely free to use. PlagTracker is a multifaceted online tool that meets the diverse needs of students. Turnitin and PlagTracker has the same operations but PlagTracker is available free of cost.

8. WriteCheck: - WriteCheck is online plagiarism tool its provide plagiarism checking by Turnitin ${ }^{\circledR}$, grammar checking by ETS ${ }^{\circledR}$ technology and profession tutoring by personal tutor services. It also provide resource center for checking your essay/paper and point in the right direction, plagiarism quiz or understand about plagiarism, services. 
Write check mainly worked for student to check grammar, style, usage, mechanics, spelling and originality.

9. Glatt Plagiarism services: - This software designed by Dr. Barbara Glatt. In this service Three program added for expose and shutout plagiarism.

- Glatt Plagiarism Teaching Program (GPTP) for define direct and indirect plagiarism and how to skip it.

- Glatt Plagiarism Screening Program (GPSP) for detect plagiarism and explain that how to different from copyright infringement.

- Last, Glatt Self Plagiarism Program (GSPP) a shield program to help detect unthought show of plagiarism.

10. Plagium: - Plagium is a free online multilangual plagiarism tracker. Its only 'Copy and Paste' online scanner, no one file type like, .docx, .PPT, .pdf, supported. Its provide quick search service for plagiarism, deep search for depth plagiarism checking and file comparison, for compare with uploaded files and URLs. Weekly alert service for regular users are also available. This software is able to handle check with large blocks of text. This software allows 2000 words per search at a time.

11. iThenticate:- iThenticate is developed by Turnitin. iThenticate is the leading provider of professional plagiarism detection and prevention technology used world-wide by scholarly. Publishers and research Institutions that ensures the originality of written work prior to publications.

iThenticate helps editors, writers, professionals, scholars, prevent misconduct by comparing manuscript against its database of our 60 billion web pages, 155 million content items including 49 million works from 800 scholarly publisher participates of Cross Check, a service presented by CrossRef and powered by iThenticate Software.

12. URKUND: - URKUND is a fully automatically system for handling plagiarism. When a student submit his thesis/dissertation. The Supervisor use URKUND Software to detect plagiarism

URKUND matches submitted data with three different sources:-

- The Internet

- Previously Submitted Student's Data (33 + Million, October 2017)

- Published material (Books, Journal, Report's etc.)

If URKUND find any similarity with above three content, it will flag it for possibility of plagiarism. Then the system sent a mail to the supervisor with his analysis.

13. JPlag: JPlag is a web service that finds pair at similarity program among a given set of programs. JPlag has a powerful user interface for understanding the results. JPlag is resource efficient and scales to large submission. Java is easy to use but it also available in $\mathrm{C}, \mathrm{C}++$, and Scheme.

\section{Strategy for Detection}

- As you read the articles, look for enclose evidence that may be point to plagiarism. Among the clues are following -

A) Mixed citation styles

B) Absence of quotations or references.

C) Paper Formatting

D) Outside Topic

E) Oddity with Style or Spelling

F) Smoking Guns.

- The Source of papers/articles must be read. 
- Search URLs if paper online.

- Use plagiarism detectors like software, Plagiarism Resource Centre etc.

\section{CONCLUSION}

After studying the measures it is said that plagiarism is a crime. It will be happen then do not describe the author name and his literate details and if information will be online then must have URL.

Plagiarism mostly seen in the students. Students use the ideas, words of any author in their dissertation, projects, thesis without any proper citation. Students should be made aware of this for plagiarism prevention.

There are some chances that some users may use copy-paste method from the site. Plagiarism detection give permission to keep your essay antiplagiarism and checkout if it is also available somewhere else on the web are not. To check the reality of the content of your work such as an article, poem or essay, use a high quality Plagiarism Checker to find out if your content is Plagiarise or not. This is the citation that is common for library professionals, research scholars and students also.

Firstly, organization create a strict policy on plagiarism such as that of ACM (Association for Computing Machinery) this policy define about plagiarism, self-plagiarism and as well as define punishment. Legal action public humiliation and fines include in punishment criteria.

We must understand that failing this serious obligation will have dire consequences for the future social and the economic wellbeing of the world. Therefore, Plagiarism is a problem that must not be overlooked or swept under the rug.

\section{REFERENCE}

[1] http://www.scanmyessay.com

[2] http://en.writecheck.com

[3] Stanler, Ronald B.(2012).Plagiarism in colleges in USA.(www.rbs2.com/plag.pdf)

[4] http://www.plagiarism-detector.com

[5] http://www.duplichecker.com

[6] http://www.turnitinUK.com/

[7] http://www.plagiarism.com/

[8] http://www.iThenticate.com/

[9] http://www.URKUND.com

[10] http://help.blackboard.com/

[11] http://kmbigalk.tripod.com/

[12] Prechelt, Lutz. (2000). JPlag: Finding Plagiarism among a set of program. G Germany.p.5

[13] http://www.Wame.org/

[14] Kljajic B. Rjecnik Stranih rijeci.Zegreb:Nakladni Zavod;1990.p.1052

[15] Marsh, Bill (2007).Plagiarism: Alchemy and Remedy in Higher education. State university of New York.

[16] http://www.plagium.com

[17] http://www.jplag.ipad.kit.edu

[18] http://www.plagiarism-checker.com 